\title{
Oversigt over afhandlinger vedrørende sønderjysk historie i tyske tidsskrifter 1953-54
}

\section{Ved Peter Kr. Iversen.}

En og anden vil måske finde det lidt mærkeligt, at der i nærværende oversigt kun er medtaget bidrag i tyske tidsskrifter. Imidlertid er forholdet det, at de danske tidsskrifters indhold er registreret i Dansk Tidsskrift-Index, der udgives af Statens Bibliotekstilsyn og udkommer årligt. En fuldstændig oversigt over litteraturen vedrørende Slesvig og Holsten gives $i$ den af Gesellschaft für schleswigholsteinische Geschichte udgivne Bibliographie zur schleswig-holsteinische Geschichte und Landeskunde, men denne vigtige og uundværlige håndbog for enhver, der arbejder med sønderjysk historie, er på grund af krigsforholdene blevet lidt bagefter. Det sidste fuldstændige bind omfatter tiden 1939-44, men i løbet af kort tid vil bibliografien for tidsrummet 1945-50 også væere afsluttet.

Nærværende oversigt tilstræber fuldstændighed for de i nedennævnte fortegnelse opførte tidsskrifter. Ved jævnføring med den tilsvarende fortegnelse i Sønderjydske årbøger 1953, s. 205 vil det ses, at de registrerede tidsskrifter ikke er helt de samme. En dei er enten ikke udkommet 1953-54, eller også er det ikke lykkedes inig at få fat i dem. Det gælder Jahrbuch des Nordfriesischen Instituis, Jahrbuch des nordfriesischen Vereins für Heimatkunde und Heimatliebe og Mitteilungen der Gesellschaft für Kieler Stadtgeschichte. Skulde det vise sig, at disse tidsskrifter er udkomne i årene 1953—-54, vil deres indhold, for så vidt det vedrører sønderjysk historie, blive meddelt $i$ en senere oversigt*).

På den anden side er der denne gang medtaget nogle tidsskrifter, som dels er nye og dels ved sidste registrering er undgået min opmærksomhed. Af disse nye tidsskrifter er der grund til særskilt at nævne Jahrbuch für die schleswigsche Geest, hvoraf 1. årgang, der

*) Det af Grenzfriedensbund udgivne Grenziriedenshefte har jeg først haft adgang til, efter at arbejdet med oversigten var afsluttet. De historiske og grænsepolitiske artikler i dette tidsskirft vil blive nævnt i en senere oversigt. 
udkom 1953, blev udgivet af Arbeitsgemeinschaft für Landes- und Volkstumsforschung Schleswig, medens årgangene 1954 og 1955 er udgivet af den nyoprettede Heimatverein Schleswigsche Geest, der dæekker området mellem Angel og de frisiske marskegne. Årbogen, der redigeres af den erfarne og meget kyndige leder af det lokalhistoriske arbejde i Sydslesvig, dr. P. Ingwersen, slutter pænt op i rækken af de ovrige sydslesvigske hjemstavnsforeningers årbøger. Disse adskiller sig iøvrigt fra danske amtshistoriske årbøger derved, at de foruden lokalhistoriske bidrag også bringer naturhistorisk stof, digte og små hjemstavnsfortællinger. Så langt den overvejende plads optages dog af de lokalhistoriske afhandlinger, som i kvalitativ henseende ingenlunde står tilbage for, hvad der fremkommer i danske amtshistoriske ărbøger, en og anden vil måske endda sige tværtimod.

Efter at Sippe der Nordmark ophørte med at udkomme under krigen, havde den slesvig-holstenske slægtsforskning i nogle år intet meddelelsesorgan. Interessen for det slægtshistoriske arbejde var dog stadig levende, og 1949 kunde en nyoprettet forening Gesellschaft für schleswig-holsteinische Familienforschung und Wappenkunde påbegynde udsendelsen af et lille meddelelsesblad, hvoraf der hidtil er udkommet 6 hæfter, de første fem redigeret af professor G. Rendtorff, Kiel, det sidste af den på mange felter aktive dr. G. E. Hoffmann, lederen af det slesvig-holstenske Landesarchiv på Gottorp.

Af de ovrige tidsskrifter er der grund til at standse lidt op ved Kunst in Schleswig-Holstein, der begyndte at udkomme 1951, og hvoraf der nu er udsendt fem bind. Tidsskriftet udsendes som årbog for det slesvig-holstenske landsmuseum på Goltorp og redigeres af Ernst Schlee. Foruden egentlige kunsthistoriske afhandlinger bringes der også enkelte digte og andre skønlitterære bidrag. Årbogen, der udkommer på Christian Wolffs forlag i Flensborg, har et fornemt udstyr og er rigt illustreret. Selv om kun en del af afhandlingerne vedrører sønderjyske forhold, vil kunst- og kunsthistorisk interesserede danske kunne have fornøjelse og udbytte af at stifte nærmere bekendtskab med denne årbog. Ofte peges heri på vekselvirkningen og den gensidige befrugtning, som har fundet sted mellem tysk og dansk kunst i græenselandet og $\mathrm{i}$ det hele taget.

Den samme venlige og sympatetiske indstilling over for dansk kultur møder læseren naturligvis i Nordelbingen, Hedemann-Heespens gamle tidsskrift, der nu redigeres af museumsdirektør, dr. Fritz Fuglsang, Flensborg, dr. Harry Schmidt, Kiel og Landesbibliothekar dr. Olaf Klose, Kiel. Nordelbingen udgives af Gesellschaft für schleswigholsteinische Geschichte og bringer afhandlinger vedrørende kunst, folkekultur, litteratur og forhistorie. Fra 22. bind bringes her end- 
videre landskonservatorens udførlige årsberetninger vedrørende "Denkmalpflege" samt anmeldelser af litteratur vedrørende tidsskriftets emneområder, som hidtil har været publiceret i Zeitschrift der Gesellschaft für schleswig-holsteinische Geschichte. Dette, det førende slesvig-holstenske historiske tidsskrift, der især bringer afhandlinger vedrørende den politiske, administrative og økonomiske historie, har fra 1952 som hovedredaktør haft Landesbibliothekar dr. Olaf Klose, og den høje standard, som hidtil har præget dette tidsskrift er opretholdt under den nye redaktor. Af stor betydning er tidsskriftets anmeldelser af historisk litteratur.

løvrigt er følgende tidsskrifter gennemsete. Den ud til højre for hvert tidsskrift angivne forkortelse er anvendt i oversigten.

Beiträge zur Landeskunde von Schleswig-Holstein. Herausgegeben von Carl Schott (Schriften des Geographischen Instituts der Universität Kiel) $1953 \ldots \ldots \ldots \ldots \ldots \ldots \ldots \ldots$. z. L.

Germania. Anzeiger der römisch-germanischen Kommission des deutschen archäologischen Instituts, årg. 31, 1953 ........ Germania

Die Heimat. Monatschrift des Vereins zur Pflege der Natur und Landeskunde in Schleswig-Holstein 1953-54 .........

Hansische Geschichtsblätter. Herausgegeben vom Hansischen

Geschichtsverein, 72. årg., $1954 \ldots \ldots \ldots \ldots \ldots \ldots \ldots \ldots \ldots$ H. G.

Hammaburg. Vor- und frühgeschichtliche Forschungen aus dem

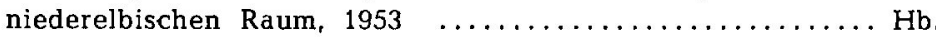

Jahrbuch des Angler Heimatvereins 1953-54 .......... Jb. A. Jahrbuch der Heimatgemeinschaft des Kreises Eckernförde

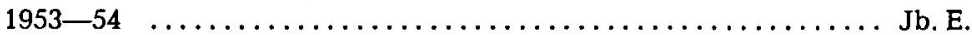

Jahrbuch für die schleswigsche Geest $1953-55 \ldots \ldots \ldots \ldots \ldots$ Jb. G. Anm.: Årgang 1955 udkom 1954.

Heimatkundliches Jahrbuch für den Kreis Rendsburg 1953-54.. Jb. R.

Kunst in Schleswig-Holstein. Jahrbuch des schlesw.-holst. Landesmuseum Schleswig/Schloß Gottorp 1953-55 ........ K. S-H Anm.: Årgang 1955 udkom 1954.

Mitteilungen der Gesellschaft für schlesw.-holst. Familienforschung und Wappenkunde 1949-53, hæfte $1-6 \ldots \ldots \ldots . .$.

Nordelbingen. Beiträge zur Heimatforschung in SchleswigHolstein, Hamburg und Lübeck, 1953-54 ............

Norddeutsche Familienkunde. Zeitschrift der Arbeitsgemeinschaft genealogischer Verbände in Niedersachsen 1. og 2.

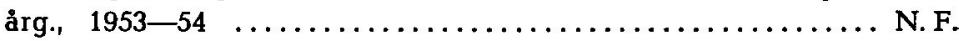

Offa. Berichte und Mitteilungen aus dem schlesw.-holst. Landesmuseum für Vor- und Frühgeschichte in Schleswig und dem Institut für Ur- und Frühgeschichte der Universität Kiel, 1953 O. 
Schleswig-Holstein. Monatschrift für Heimat und Volkstum,

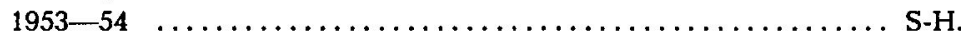

Schriften des Vereins für schlesw.-holst. Kirchengeschichte,

2. rk. 12. bd. $1953 / 54 \ldots \ldots \ldots \ldots \ldots \ldots \ldots \ldots \ldots \ldots \ldots$ Schr.

Zeitschrift der Gesellschaft für schlesw.-holst. Geschichte,

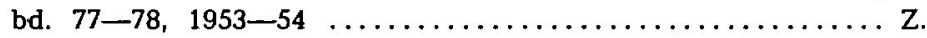

Zeitschrift für Niedersächsische Familienkunde. Herausgegeben durch die Zentralstelle für Niedersächsische Familienkunde,

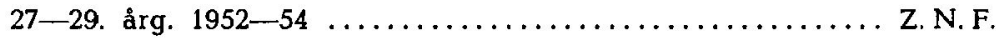
Andre anvendte forkortelser: Bind $=$ bd., død $=$ d., født - f., række $=$ rk., side og $\operatorname{sogn}=\mathbf{s}$.

Arkiver, biblioteker, museer $\mathrm{m}$. v.

1) G. E. Hoffmann: Ueber Kirchspielarchive, Jb. G. 1954, s. 134-138. 2) M. Martensen: Archivpflege. Inhalt eines Kirchenarchivs (Kvarn), Jb. A. 1953, s. 215-17. - 3) W. Trede: Die Archivbestände der Kirchspiele in der ev.-luth. Propstei Hütten, Jb. E. 1954, s. 177-208. - 4) A. Ketelscn: Das volkskundliche Archiv von Bruno Ketelsen. Ihr Ziel, Aufbau und Inhalt, Jb. G. 1954, s. 51-55. - 5) G. E. Hoffmann: Von den Siegeln der Arendsharde, Jb. G. 1955, s. 64-69. - 6) E. Assmann: Siegel und Wappen cier Stadt Rendsburg, Z. 1954, s. 206-223. - Arkivvæsen: se endv. nr. 62 . -

7) P. Callesen: Kurzer geschichtlicher Aufriss des Büchereiwesens in Nordschleswig, H. 1953, s. 31-33. - 8) Grönhoff: Dichterzimmer in der Landesbibliothek, H. 1953, s. 299.

9) O. Klose: Die dänischen Kulturhistorischen Museen, S-H. 195?, s. 279-81. - 10) P. Hirschfeld: Bericht des Landesaintes für Denkmalpflege Schlesw.-Holst. über die Jahre 1952 und 1953, N. 1954, s. 187-204. - 11) Aus der Arbeit des Landesmuseums, K. S-H. 1953, s. 199-207, 1954, s. 179-186, 1955, s. 161-174. - 12) E. Schlee: Volkskunde Schlesw. Holst.s im schlesw.-holst. Landesmuseum, S-H. 1954, s. 32-34. - 13) H. Holtorf: Zwischen Vergangenheit und Zukunft. Dem Flensburger Muscum zur 50. Wiederkehr des Tages seiner Eröffnung, S-H. 1953, s. 230-33. - 14) Ellen Redlefsen: Die Friedrichstädter Stube im Flensburger Museum, H. 1953, s. 148-150. - 15) E. Redlefsen: Begegnung mit chinesischer Malerei in Flensburg, S-H. 1954, s. 65-66. - Flensborg museum se endv. nr. 152. - 16) F. Zachi: Die letzte Hallig-Windmühle kam ins Friesen-Museum, S-H. 1953, s. 312. - 17) R. Brügge: Ein Gang durch die Ausstellung "Eckernförder Stajtgeschichte, Jb. E. 1954, s. 33-38. -

\section{Hjemstavnshistorie (opovelse og mål)}

1E) W. Danielsen: Heimat, Volkstum und Geschichte, S-H. 1954, s. 27-28. - 19) H. Greiss: Kunsterziehung und Heimatforschung. Aus der Arbeit der Pädagogischen Hochschule Kiel, K. S-H. 1953, s. 54-67, - 20) Mitteilungen der Arbeitsgemeinschaft für Landes- und Volkstumsforschung, 
H. 1953 , s. $240-41,284,1954$, s. $19-21,125,201-02 .-21)$ P. Ingwersen: Alte Bauerngeschlechter in Klein und Gross Rheide. Eine Arregung, Jb. G. 1955, s. 205-208. - 22) P. Selk: Mit dem Notizbuch unterwegs, S-H. 19১4, s. $34-35$. - Se endv. nr. 330 .

\section{Forhistorie og arkæologi.}

23) (Fundberetninger fra Sydslesvig og Holsten), Germania 1953, s. 228-245. - 24) H. Jockisch: Vorgeschichtsfunde 1953/54, im Kreisgebiet (Eckernførde kreds) Jb. E. 1954, s. 89-92. - 25) K. W. Struwe: Kugelamphoren aus Holstein, O. 1953, s. 1--13. - 26) H. Jockisch: Neue Funde aus den Muschelhaufen am Windebyer Noor. (Ertebøllekultur), Jb. E. 1953, s. 83-84. - 27) H. Schwabedissen: Fruchtschalen aus Schlesw.- Holst. und ihre Zeit, O. 1953, s. 14-66. - 27a) R. Schindler: Die Entdeckung zweier jungsteinzeitlicher Wohnplätze unter dem Marschenschlick im Vorgelände der Borberger Dünen und ihre Bedeutung für die Steinzeitforschung Nordwestdeutschlands, Hb. 1553 , s. 1-17. - 28) J. Röschmann: Hünengräber in Angeln, Jb. A. 1954, s. 72-91. - 29) F. H. Hamkens: Der Dronninghoi, Jb. A. 1953, Jb. A. 1954 , s. $72-91$. - 29) F. H. Hamkens: Der Dronninghoi, Jb. A. 1953, s. 36-49. - 30) H. Drescher: Eine technische Betrachtung bronzezeitlicher Halskragen, O. 1953, s. 67-72. - 31) P. la Baume: Die Ausgrabung im Skalnastal auf Amrum 1952, O. 1953 s. 82-87. - 32) G. Timmermann: Schiffskundliche Betrachtung an zum Hirschsprungsboot, N. 1953, s. 20-30. - 32a) K. Waller: Die Todendorfer Schale von Holszel, Hb. 1953, s. 53-56. 33) H. Hinz: Eine germanische Sauna aus Rantrum, Kr. Husum, H. 1953, s. 20-22. - 34) H. Hinz: Eine vorgeschichtliche Getreidedarre, H. 1954, s. 213-14. - 35) R. Schütrumpf: Neue Untersuchungen zur jüngeren Vegetations- und Siedlungsgeschichte Angelns, Jb. A. 1953, s. 33-36. - 36) E. G. J. Knoop: Die Völkerschaften unseres schlesw.-holst. Landes zu Beginn unserer Zeitrechnung, H. 1953, s. 247-51. - 37) J. Röschmann: Ein germanisches Dorf der römischen Kaiserzeit. 1-3. Jahrh. nach Chr. Geò. bei Esmarksüderfeld, Jb. A. 1954, s. 91-98. - 38) G. Schäfer: Vorgeschichtliche Feldeinteilungen in Angeln, Jb. A. 1954, s. 67-71. - 39) H. Jankulun: Neue Gesichtspunkte zur Besiedlungsgeschichte Angelns in der Eisenzeit, Jb. A. 1954, s. 37-57. - 40) H. Hingst: Vorgeschichtliche Eisengewinnung auf der schleswiger Geest, Jb. G. 1955, s. 35-47. - 41) Hans Hingst: Eisengewinnung und Siedlung im Kreis Rendsburg in vorgeschichtlicher Zeit, Jb. R. 1953, s. 54-66. - 42) K. Schlabow: Zwei Moorleichenfunde aus dem Domlandsmoor, Gemarkung Windeby, Kreis Eckernförde, Jb. E. 1954, s. 79--88. - 43) H. Hinz: Ein Moorfund aus Almdorf, Kreis Husum, N. 1353, s. 12-19. - 43a) K. Radatz: Ein Waffenfund der früheren Merowingerzeit aus der Unterelbe (Våten af nordisk oprindelse), Hb. 1953, s. 35-44. 44) H. Hingst: Ein verzierter Stab von Wattenbek, Kr. Rendsburg. (ca. 900 e. Kr.), O. 1953, s. 79-82. - Ang. en nyfunden runesten og skålsten se nr. 125. - 45) W. Hübener: Die stratigraphischen Grundlagen 
der Keramik von Alt-Lübeck auf Grund der Ausgrabung von 1949., O. 1953, s. 87-111. - 46) H. Jankuhn: Ein reiches Grab der Wikingerzeit aus Schwansen, Jb. E. 1953, s. 76-81. - 47) H. Jankuhn: Schatzfunde der Wikingerzeit in Angeln, Jb. A. 1953, s. 27-32. - 48) H. Jankuhn: Ein Burgentyp der späten Wikingerzeit in Nordfriesland und sein historischer Hintergrund, Z. 1954, s. 1-21. - 49) H. Jankuhn: Zur Topographie frühmittelalterlicher Stadtanlagen im Norden und zur Soziologie ihrer Bewohner, B. z. L. 1953, s. 81-104. - 50) W. Hübner: Zur Topographie von Haithabu, Germania 30. bd., 1952, s. 76-88. - 51) W. Hübener: Keramik in Haithabu, Jb. A. 1954, s. 99-105. - 52) H. Hinz: Zum Stand der Mildeburgforschung, H. 1953, s. 306-07. - 53) A. Busch: Nochmals: Zum Stand der Mildeburgforschung, H. 1954, s. 225. - 54) D. Stichtenot: Farria vel Heiligland und das Rügenheiligtum. Eine Entgegnung, Z. 1953, s. 184-195. - 55) D. Stichtenoth: Die heilige Insel, Z. 1954, s. 280-84. - 56) W. Laur: Noch einmal Heiligland und Forsitesland, Z. 1954, s. 272-80. -

\section{Almindelig historie.}

57) H. Ammann: Deutschland und die Tuchindustrie Nordwesteuropas im Mittelalter ( mit 12 Karten), H. G. 1954. s. 1-63. - 58) E. v. Lehe: Der holsteinische Adel im Mittelalter, Z. N. F. 1953, s. 25-32, 49-56. 59) E. Assmann: Salvo Saxoniae limite. Ein Beitrag zum Problem des Limes Saxoniae, Z. 1953, s. 195-203. - 60) E. Assmann: Schleswig-Haithabu und Südwesteuropa, Z. 1954, s. 284-88. - 61) R. Irmisch: Die Handfeste. Das Ripener Privileg Christians I. S-H. 1954, s.136-137. - 62) A. Scharff: Das Ripener Privileg von 1460 im Kopenhagener Reichsarchiv, S-H. 1954, s. 198. - 63) D. Puls: Christian II in Sonderburg, H. 1954, s. 47-49. - 64) P. Ingwersen: Herzog Johann der ältere als Volkserzieher, H. 195.3, s. 47-48. - 65) P. Ingwersen: Die Auswirkungen der Kriege des 17. Jahrhunderts auf die mittelschleswigsche Geest, Jb. G. 1953, s. 35-44. 66) E. Erichsen: Wie die Dänen in den Herzogtümern das Salzmonopol einführten $(1737 / 3 \varepsilon)$, H. 1954 , s. 53-54. - 67) D. W. Schumann: Französische Emigranten in Schleswig-Holstein. Ein Kapitel aus der europäischen Kulturgeschichte um 1800, N. 1953, s. 121-149. - 68) D. W. Schumann: Neue Studien zur französischen Emigration in Schleswig-Holstein, N. 1954, s. 134-156, - 69) Fr. Hoffmann: Schleswig-Holsteins Volksaufbau zu Anfang des 19. Jahrhunderts, Z. 1954, s. 293-299. - 70) M. Rasch: Der 7. Wahldistrikt der kleineren Landbesitzer und sein Vertreter in der ersten schleswigschen Ständeversammlung, Jb. G. 1955, s. 102-116. - Ang. Kiels universitet og den tyske toldforening se nr. 115. - 71) M. Rasch: Aus Tondener Amts-Akten der Erhebungszeit, H. 1954, s. 64-71. - 72) W. Friccius: „Oprør«. Eine kleine Betrachtung zum 24. März 1848, S-H. 1954, s. 67-68 73) E. Erichsen: Reformregungen und Gesetzeswünsche als Hintergrund der Erhebungszeit 1848-51, H. 1953, s. 27-30. - Ang. 1848-64 se endv. nr. $111,262,296,376,378 .-74)$ Th. O. Achelis: Die staatsgefährlichen Mützen 
der Meldorfer Primaner, H. 1953, s. 311-312. - 74a) Fr. Sparmann: Pastor Thun in Bergstedt und seine Absetzung durch die dänische Regierung 1854, Jahrb. des Alsterverein 1954. - 75) H. Schmidt: Als es im Kriege noch menschlicher zuging. Preussen und Oesterreicher 1864 in Fredericia. Aus den Erinnerungen Johs. Ahlmanns, S-H. 1954, s. $178-182$. - 76) E. Erichsen: Wie Herzog Friedrich um die Krone kam. Aus dem Primkenau-Archiv, S-H. 1954, s. 86-88. - 77) E. Freytag: Wrangel in Sieverstedt, S-H. 1953, s. 46-48. - 78) N. Eggers: Oeversee 1864, Jb. G. 1954, s. 115-123. - 79) E. Erichsen: Angler Stimmungsbilder 1864, Jb. A. 1951, s. 134-142. - 1864, se endv. nr. 334. - 80) E. Erichsen: Kopenhagener diplomatische Relationen Sommer 1870, S-H. 1954, s. 218. - 81) Chr. Hansen: Der deutsche Ausschuss für das Herzogtum Schleswig in Berlin 1918--20, S-H. 1954, s. 56. - 82) L. Specht: Der Pendelverkehr der schlesw-holst. Städte und Hamburgs. - Se endv. nr. 272 og 295.

\section{Grænsepolitik.}

83) E. Edert: Der 6. September 1953. (Forbundsdagsvalget) S-H. 1953, s. 251. - 84) U. Hahn: Unser Grenzland und das Programm Nord, H. 1954, s. 205-209. - 85) Ministerpräsident von Hassel über das deutsch-dänische Minderheitenproblem. (Af regeringserklæringen 8/11 1954), S-H. 1954, bilag. - 86) H. Hönig: Unruhe an der Nordgrenze, S-H. 1954, bilag. - 87) H. Jensen: Der Durchbruch der dänischen Bewegung, S-H. 1954, s. 297-99. 88) Wilh. Jürgensen: Heimat als politische Kraft, S-H. 1953, s. 278-79. 89) H. Kardell: Entscheidung zwischen Nord und Süd. Zeugnisse dänischer Historiker und Politiker, S-H. 1953, s. 203-204. - 90) Menzel: Funktionen der Minderheiten im gegenwärtigen Europa, S-H. 1954, bilag. - 91) M. Molsen: Gedanken zur deutsch-dänischen Grenzauseinandersetzung, $\mathrm{S} \cdot \mathrm{H}$. 1953, s. 22-24. - 92) H. Schmidt: Bekenntnisse auf dem Schlachtfeld von Idstedt, (foredrag) S-H. 1954, s. 227. - 93) H. Schmidt: Die Idee eines neuen Schleswig-Holsteins. Sinn und Ziel des Heimatbundes, S-H. 1953, s. 3-4. - 94) H. Schmidt-Gorsblock: Um die deutsche Schule Nordschleswigs, S-H. 1953, s. 227-28. - 95) M. Steinhäusser: Geschichte und Grenzaktivismus. Prof. Fabricius und die Schleswig-Frage, S-H. 1953, s. 118-119. - 96) M. Steinhäuser: Die zweite und dritte Zone, S-H. 1953, s. 67-68. - 97) $\mathrm{M}$. Stēinhäuser: S. S. V. und S. S. W. - Mitglieder und Wähler. (Forbundsdagsvalget), S-H. 1953, s. 252. - 98) M. Steinhäuser: Irredenta oder loyale Minderheit? S-H. 1953, s. 276-277, - 99) M. Steinhäuser: Zwischen Schlei und Eider, Jb. E. 1953, s. 5-8. - 100) K. Thomsen: Programm Nord - der Deich wird geschlossen, S-H. 1954, s. 272-273. - 101) Jahresbericht des schlesw-holst. Heimatbundes. Orts- und Kreisverein Rendsburg., Jb. R. 1953, s. 145-146. - 102) Aus der Arbeit des schlesw.-holst. Heimatbundes '(i Rendsborg kreds) Jb. R. 1954, s. 166-167. - Se endv. nr 121.

I Schleswig-Holstein findes månedlige oversigter over udviklingen' i Nord- og Sydslesvig. Endvidere henvises til det af Grenzfriedensbund ud- 
givne Grenzfriedenshefte, hvori der ud fra et moderat tysk standpunkt bringes artikler ang. grænseforhold.

\section{Administration og retshistorie.}

Se nr. 248, 249 258, 287, 327, 396.

\section{Befolkning.}

I almindelighed, se nr. 69, $\varepsilon 2,240,298,332,333$, Adel se nr. 38. Gejstlighed, se nr. 113, 343-346. Embedsmænd iøvrigt, se nr. 341, 342. Studenter, se nr. 338-340. Franske emigranter, se nr. 67-68. Inderster, se nr. 178--180. Livegne, se nr. 348 .

\section{Kirkehistorie.}

103) Sr. H. Hamkens: Die Sage vom Kirchenbaumeister, H. 1954, s. 118-121. - 104) H. Koeppen: Eine unbekannte Supplik des Bischofs Helembert von Schleswig [1342, 21/11], Z. 1953, s. 203-207. - 105) W. Jensen: Die Visitationsreise des schlesw.-holst. gottorpischen Generalsuperintendenten Mag. Jacobus Fabricius im Jahre 1639 (II), Schr. 2. rk. 12. bd. s. 1-34. - 106) E. Freytag: Die Einkünfte der Geistlichen und Küster der Uggel- und Wiesharde im 17. und in der ersten Hälfte des 18. Jahrh., Jb. G. 1954, s. 60-72. - 107) E. Schwalm: Pietismus und Politik in Schlesw.-Holst., Schr. 2. rk. 12. bd. s. 175-179. - 108) O. Scheel: Pietismus, Christiansfeld und Dalbyhof II, Schr. 2. rk. 12. bd., s. 59-82. - 109) H. Beyer: Die Geestbauern und Adlers Kirchenagende 1797-1800, Jb. G. 1955, s. 23-31. 110) H. Beyer: Eckernförder Landvolk im Kampf um den "alten Glauben « (1797/1800). Zu der Adlerschen Kirchenagende, Jb. E. 1954, s. 7-16. 111) E. Freytag: Johann Hinrich Wichern und die Feldseelsorge in der schlesw.-holst. Armee, Schr. 2. rk. 12. bd. s. 130-132. - 112) W. Göbell: Kirchliches Leben um die letzte Jahrhundertwende. Ein Beitrag zum Protestantismus in Schlesw.-Holst., N. 1954, s, 168-186. - 113) G. Faust: Schlesw.-holst. Kandidaten in Galizien, Schr. 2. rk. 12. bd., s. 133-146. Kirkehistorie, se iøvrigt nr. 236, 374, 405.

\section{Skolehistorie.}

114) H. Schmidt: Landgraf Carl zu Hessen-Cassel wird vierfacher Ehrendoktor. Ein Beitrag zur Geschichte der Universität Kiel, Z. 1953, s. 208-18. - 115) Fr. Hoffmann: Die Stellung der Kieler Universitätswissenschaft zu Schleswig-Holsteins Beitritt zum Deutschen Zollverein, Z. 1953, s. 167-183. - 116) K. Gevenich: Die Geschichte des Landwirtschaftstudiums in Kiel, H. 1954 , s. $1-3$.

117) Th. O. Achelis: Dänischer Unterricht und dänische Schüler auf dem Haderslebener Johanneum in preussischer Zeit, Z. 1953, s. 218-227.

118) E. Erichsen: Die Schulverhältnisse in Angeln und die adlersche Schulreform (Nachtrag), Jb. A. 1953, s. 105-114. - 119) E. Freytag: Beiträge zur 
Geschichte des ländlichen Schulwesens in der Uggel- und Wiesharde, Jb. G. 1955 , s. 47-59. -- Degneindkomster i Ugle og Vishrdr., se nr. 106. 120) H. Schmidt: Schulidyll um 1800, H. 1953, s. 241. -- Ang. skoler, se endv. nr. 262, 270, 306, 313, 314, 324, 328. - 121) Fr. Christensen: Die Folgen des deutschen Zusammenbruches 1945 für das deutsche Schulwesen Nordschleswigs, H. 1954, s. 25-32.

122) E. Erichsen: Die erste landwirtschaftliche Schule Angelns in Oersberg, H. 1953, s. 43-45. - 123) C. Lunau: Zur Gechichte der ersten landwirtschaftlichen Schule zu Oersberg in Angeln, H. 195-1, s. 249-50. -

\section{Sprog og stednavne.}

124) W. Laur: Die sprachlichen Verhältnisse in Angeln in ihrer geschichtlichen Entwicklung, Jb. A. 1953, s. 50-73. - 125) K. Henkel: Der Runenstein und die Schalensteine von Medelby, Jb. G. 1955, s. 180-184. - 126) P. Ingwersen: Sprachen die Leute auf der mittelschleswigschen Geest in früheren Jahrhunderten auch plattdeutsch, Jb. G. 1954, s. 30-42. - 127) R. Runde: Wird sich die plattdeutsche Sprache weiterhin behaupten können?, S-H. 1953, s. 55. - Sproghistorie, se endv. nr. 219, 221, 333. -

128) O. Clausen: Die bäuerliche Arbeit im Spiegel der Flurnamen, Jb. G. 1954, s. 56-59. - 129) W. Laur: Die Ortsnamen im Kreise Eckernförde, Jb. E. 1953 , s. $40-44$. - 130) W. Laur: Die Ortsnamen im Kreise Reñdsburg, Jb. R. 1954, s. 45-86. - 131) W. Laur: Die Ortsnamen auf dem Mittelrücken, Jb. G. 1953, s. 79-87. - 132) W. Laur: Theophore Ortsnamen in der Landschaft Angeln, Jb. A. 1954, s. 106-118. - 133) W. Laur: Flussnamen im Landesteil Schleswig, H. 1953, s. 4-9. - 134) O. Clausen: Falsch geraten (sted- og flodnavne i Sorge og Trene området), H. 1953, s. 159-161. - 135) Johs. Herting og W. Laur.: Der Strassenname »Lollfuss $«$ in Schleswig und Wesselburen, N. 1953, s. 175-176. - 136) L. Oesau: "Hundeschläger-Fenne«, H. 1953, s. 234. jvnfr. s. 274. - 137) H. Bülck: Rosengarten und Rosenberg, H. 1953, s. 98-99. - Stednavne, se endv. nr. 241, 285. -

\section{Kunsthistorie og håndværk.}

138) L. Martius: Von Briefen, Bildnissen und Studienfahrten schlesw.holst. Künstler aus der Zeit der Romantik, K. S-H. 1954, s. 59-87. - 139) S. A. Hallbäck: Künstlerische Verbindungen zwischen Schlesw.-Holst. und West-Schweden im 18. Jahrh., N. 1953, s. 116-121. - 140) H. Siebel: Auswirkung der Reformation auf das Kunsthandwerk in unserem Lande, $H$. 1954, s. $282-84$. - 141) W. J. Müller: Vom Kunsthandwerk in Schlesw.Holst. Meister des einheimischen Kunsthandwerks, K. S-H. 1954, s. 9-32. 142) H. Holtorf: Schlesw.-holst. Kunst in der Gegenwart, S-H. 1953, s. 155156. - 143) W. Johnsen: Kunstdenkmäler in der Sage, K. S-H. 1953, s. 68 -81. - 144) H. J. Kuhlmann og H. Appuhn: Im Umkreis des Gottorper Hofes, K. S-H. 1955, s. 179-183. - 145) E, Schlee, W. Wolke, H. Schmidt, 
B. Riewerts: Aus der Kunst- und Kulturgeschichte des Gottorper Hofes, K. S.-H. 1953, s. 186-198. - Gottorperglobus, se nr. 321. -

Bygningshistorie, se nr. 166-168, 233-235, 237--238, 245, 247, 261, 278, $283,305,318,320,322,416$.

146) Fr. Fuglsang: Bemerkungen zur Holzplastik des 13. Jahrhunderts im Herzogtum Schleswig, N. 1954, s. 42-59. - 147) H. Appuhn: Die Idstedter Madonna, S-H. 1954, s. 314. - 148) W. Johnsen: Der Bildschnitzer Hans Pahl (gest. 1714 in Rendsburg). Neue Aufschlüsse zur Ausstattung der Christkirche in Rendsburg, zugleich ein Beitrag zur Geschichte der volkstümlichen Schnitzkunst in Schlesw.-Holst., Jb. R. 1954, s. 22-45. - 149) G. Reimer: Hans Peper, Hans Sander — Rendsburger Bildschnitzer, H. 1954, s. 315-17. - 150) H. Siebel: Der Abendmahlschrank aus Rott im Ostenfelder Haus in Husum (1642), S-H. 1953, s. 188. -

Billedskærerkunst, se endv. nr. 366, 380.

Billedhuggerkunst, se nr. 384.

151) E. Redlefsen: Schlesw.-holst. Maler in Italien, S-H. 1953, s. 105-107. - 152) E. Redlefsen: Niederländische Malerei in schlesw.-holst. Privatbesitz (udstilling på Flensborg museum), S-H. 1954, s. 206-208. - 153) E. Schlee: Nordfriesische Laienmaler, K. S.-H. 1953, s. 82-111. - 154) H. Schmidt: Nochmals: Ein Gemälde von Friedrich Adolf Ovens, N. 1954, s. 75. 155) H. Schmidt: Die Grablegung Christi von Jürgen Ovens, S-H. 195.4, s. 82-83. - 156) H. Schmidt: Jürgen Ovens, S-H. 1953, s. 301-05. - 157) H. Appuhn: Niko Wöhlks Ostereier, S-H. 1953, s. 109. - 158) G. Wietek: Die Asmus Carstens Ausstellung in Schleswig, S-H. 1954, s. 169 - Maleri, se endv. nr. 360, 362, 364, 379, 388, 397, 407, 410, 417. -

159) W. J. Müller: Bemerkungen zur kunstgeschichtlichen Stellung der beiden Taufen des Michel Dibler, N. 1953, s. 84-87, se endv. nr. 367 Klokkestøberi, se nr. 301. - Kirkelig kunst, se nr. 243, 254, 265 og 319. —

Guldsmedehåndværk, se nr. 395. - 160) H. Stierling: Von alter Schützen Herrlichkeit (sølvsmedekunst), N. 1953, s. 31-39. - 161) G. Wietek: Aus Kellinghusens Fayencezeit, S-H. 1954, s. 18-19. - 162) G. Wietek: Fayencegrabungen in Kellinghusen, K. S-H. 1955, s. 175-177. - 163) A. Busch: Handwerkliche Wattfunde (14. årh.), H. 1954, s. 90-91.

164) Fr. Pauly: Wie Schleswig-Holsteiner Goethe sahen, K. S-H. 1955, s. 143-160. - 165) K. Witt: Blumenflor in wenglischen "Gefilden und Brennholzkantaten. Auch eine Nikolaus Oest Betrachtung, S-H. 1953, s. 239-240. - Litteratur, se endv. nr. 393, 394, 427-31.

\section{Landbrug og skovbrug.}

166) H. Hingst: Ostenfelder Häuser im Kreise Husum, Jb. G. 1955, s. 69-84. - 167) J. U. Folkers: Gulthaus und Gutscheune, N. 1954, s. 76-107. - 168) O. Clausen: Warum hatte das Niedersachsenhaus keinen Schornstein, H. 1953, s. 217. - Ang. ladebygning i Nr. Stapel, se nr. 325.

169) H. Carstensen: Die ländliche Siedlung in Schlesw.-Holst., H. 1954, 
s. $181-186 .-170)$ C. Degn: Parzellierungslandschaften in Schlesw.-Holst., B. z. L. 1953 , s. $134-174$ - - 171) C. Schott: Orts- und Flurformen Schlesw.Holst's, B. z. L. 1952, s. 105-133. - 172) J. Leister: Der Einfluss der Drainage auf das Landschaftsbild im Osten Schleswig-Holst'ns, B. z. L. 1953, s. 180-185. - 173) H. J. Kuhlmann: Die Satruper Siedlungskammer, Jb. A. 1954, s. 5E-66. - 174) E. Erichsen: Wirtschaft und Kultur in Angeln vor hundert Jahren, Jb. A. 1953, s. 168-189. - 175) E. Erichsen: Vor 90 Jahren, Bezeichnung, Besitzer, Grösse, Wert und Besiedlung der Güter in Angeln, Jb. A. 1954, s. 147-149. - 176) P. Petersen: Neue Siedlungsmethoden im schleswigschen Raum, S-H. 1953, s. 99-100.

177) H. Schmidt: Die Aufhebung der Leibeigenschaft im Kirchspiel Westensee. Wie stand es um Emkendorf, Jb. R. 1954, s. 136-144. - 178) Fr. Goos: Aus der Geschichte der Insten im alten Amt Hütten, Jb. E. 1954, s. 39-50. - 179) Grönhoff: Wegfallende Abgaben und Leistungen, H. 1953, s. 239. - 180) E. Schwalm: Zu Grönhoff u. Erichsen, (vedr. inderstespørgsmålet), H. 1953, s. 287-88.

181) R. Dieckmann: Die Enwicklung des Maschinenwesens in der Landwirtschaft in den letzten Jahren, H. 1954, s. 84-88.

182) Th. O. Achelis: Die ersten Kartoffeln in Schlesw.-Holst., H. 1954, s. 241-42. - 183) Fr. Hoffmann: Das Vordringen nordamerikanischer Gewächse nach Schlesw.-Holst. im 18. Jahrh., H. 1953, s. 251-53. - 184) L. Middelhauve: Die Milchwirtschaft Schlesw.-Holst's, H. 1954, s. 58-61. - 185) O. Clausen: Pferd oder Ochse? Ein umstrittenes Problem während der Heidekolonisation $1761-62$, Jb. G. 1953 , s. $45-51$. - 186) K. Thomsen: Traventhal. Zentrum unserer Pferdezucht, S-H. 1953, s. 165-166.

187) E. Freytag: Was ist ein Otting? H. 1953, s. 121. - 166) D. Thomsen. Die Ackerzahlen des Kreises Eckernförde (ny jordvurdering), Jb. E. 1953, s. $94-97$.

Landbrug, se endv. nr. 34, 116, 122-123, 128, 197, 199-200, 205, 235, 244 , $258,260,266,268-269,273,285-286,288,291-292,323$.

\section{Samferdsel.}

189) J. Raben: Post-Leitfeuer auf dem Ochsenwege in Nordschleswig, H. 1953, s. 60. - 190) H. Hinz: Die Entwicklung des Wegenetzes in Westschleswig, Jb. G. 1953, s. 16-34. - 191) J. Róschmann: Die Entwicklung des Wegenetzes im östlichen Mittelschleswig, Jb. G. 1954, s. 6-22. Veje, se endv. nr. 289.

192) G. Sandhofer: "Kumm man nich ünner die Törfwagen«. Der Torfwagen - eine kleine historische Betrachtung, Jb. G. 1953, s. 89-90. 193) D. Puls: Die erste schleswigsche Eisenbahn 1854, S-H. 1954, s. $271-72$. - Jernbane, se endv. nr. 255. - Postvæsen, se nr. 309. - 194) Joh. Grönhoff: Facharbeiter beim Bau des Eiderkanals, H. 1953, s. 310. - Nordsøkanalen, se nr. 302. - 195) Fr. Hoffmann: Von der alten schlesw.-holst. Schifffahrt, H. 1954, s. 291 - 93. - 196) J. Nagel: Die Schiffahrtsroute der Kappler 
Kopenhagenfahrer nach einer zeitgenössischen Dichtung "Die Ostsee* ron Gustav Waldemar Gardthausen, Jb. A. 1954, s. 165-170. -

Forskellige næringsveje.

Apotek, se nr. 311, mølle, se nr. 239, salthandel, se nr. 66, sivmåtter, se nr. 310, tøjindustri, se nr. 57.

\section{Folkekultur og folklore.}

197) M. Peters: Die Landtechnik im Heimatraum, Jb. A. 1953, s. $189-196$. - 198) E. Schlee: Wie das Volk sich selber darstellte, S-H. 1953, s. 75-78. - 199) W. Jürgensen: Angliter Kätneralltag um die Jahrhundertwende, S-H. 1954, s. $171-173$. - 200) E. Schlee: Die Dingwall geit rüm (ang. tingstok), Jb. G. 1953, s. 52-61. - 201) E. Freytag: Diebe und Einbrecher im Amte Flensburg, Jb. A. 1953, s. 103-104. - 202) H. Hansen: Die Ostenfelder Tracht zwischen Vergehen und Werden, Jb. G. 1954, s. 100-104. 203) E. Edert: Die Tracht des Kirchspiels Ostenfeld, S-H. 1954, s. E5-86. 204) E. Schlee: Der Gebrauch des Taufzeuges (Kasseltüchs) in Schlesw.Holst., H. 1954, s. 218-223. - 205) H. Schmidt: Pflanzen von Bäumen (føør vielse), Jb. E. 1954, s. 93-98. - 206) E. Schlee: Ein Totenbrief aus dem Schleswiger Dom, H. 1953, s. 263. - 207) A. Busch: Was ist mit dem »Pharisäer « (kaffepunch), H. 1953, s. 256-258. - 208) E. Schlee: Hausrat der Galmsbüller Halligleute im 18. Jahrh., H. 1954, s. 307-312. - 209) E. Schlee: Tierschau vor 150 Jahren (menagerier), Jb. R. 1953, s. 45-5.3. -

210) K. Radunz: Einiges vom Odd-Fellow-Orden in Schlesw.-Holst., $H$. 1953, s. $185-186 .-211)$ K. Radunz: Einiges vom Druidenorden in Schlesw.Holst., H. 1953 , s. $77-78$.

Folkekultur, se endv, nr. 12, 64, 192, 251, 304, 317.

213) P. Selk: Aus meiner volkskundlichen Sammelmaspe, Jb. A. 195:3, s. 217-19. - 214) P. Selk: Volksschwänke aus Angeln, Jb. A. 1954, s. 20-21. - 215) Chr. Hansen: Anekdoten aus Dänischwohld, Jb. E. 1954, s. 169-170. 216) E. Schärff: Beitrag zur volkskundlichen Sammlung für den Kreis Eckernförde, Jb. E. 1954, s. 167-168. - 217-218) P. Selk: Was auf der schleswigschen Geeśt erzähit wird, Jb. G. 1954, s. $47-48,1955$, s. $60-63$. - 219) W. Christiansen: Volkstümliche Redensarten aus der Karrharde, Jb. G. 1953, s. 91. - 220) B. Ketelsen: Volkskundliches aus der Karrharde, Jb. G. 1954, s. 81-82. - 221) W. Christiansen: Nachbarschaftsreim aus Kartum und Braderup Jb. G. 1953, s. 92. - 222) H. Kruse: Renaissance des Aberglaubens. Ein Beitrag zur Mythologisierung der Heimat, H. 1953, s. 180-185, s. 285-86. - 223) G. Spanjer: Renaissance des Rationalismus? H. 1953, s. 236-37. - 224) F. Zacchi: Vorschauer und Spökenkieker an der Wasserkante, H. 1953, s. 61-62. - 225) J. Raben: "Brandbäume und Brandsteine auf Alsen, H. 1953, s. 58-59. - 226) P. Ingwersen: Gelegenheitsf und (hekseri), H. 1953, s. 265. - 227) G. Reimer: Sludderei um Hexen, Jb. R. 1954, s. 155-158. - Hekse, se endv. nr. 349. - 228) P. Selk: Die Volkssage im 
geistigen Wandel, H. 1953, s. 333-36. - 229) Fr. H. Hamkens: Die Sage vom Dronninghoi, H. 1953, s. 238-39. - Ang. Dronninghøj, se endv. nr. 29. Ang. folklore iøvrigt, se nr. 4, 103, 143, 257, 267, 279, -

\section{Naturforhold.}

230) G. Wüst: Ueber Ostseesturmfluten, S-H, 1954, s. 28-30. - 231) E. W. Raabe: Salzschäden in der nordfriesischen Marscí, S-H. 1954, s. 302. Naturforhold, se endv, nr, 256, 282.

\section{Topografi}

Nordslesvig.

Had e r s lev a $\mathrm{m} \mathrm{t}$, Christiansfeld, se $\mathrm{nr}$. 108. - Haderslev: 232) Th, O Achelis: An den naseweisen Herrn Bürgermeister in Hadersleben, H. 1953, s. $191_{\text {i }}$ jvnfr. s. 280 . - Se endv. nr. 117,353 og 387 . - Skrydstrup s., se nr. 353.

Siønderborg a m t, Als, se nr. 215. - Svenstrup s., Hjortspring, se nr. 32. - Sønderborg: 233) J. Raben: Schloss Sonderburg im Wandel der Zeit, H. 1953, s. 35-38; se endv. nr. 63.

Tøn der a m t : se nr. 70-71 - Burkal s.: 234) H. Kardel: Ausgrabung bei Tondern. Ein Jagdschloss Herzog Hans des Alteren, (Grøngård) H. 1954, s. 34. - Tonder by, se nr. 347, 358, 382, 392, 408, 418.

A benra a m t: 235) D. Puls: Schloss und Amt Apenrade 1564, H. 1953, s. 33-34. - Ensted s.: 236) Fr. Christensen: Soziale Kämpfe im Schatten einer Dorfkirche. Aus einer noch nicht veröffentlichten Arbeit über das Kirchspiel Enstedt, H. 1953, s. 50-53. - Ảbenrå, se nr. 235 og 392.

Vejle a m t, Dalby s., se nr. 108.

\section{Sydslesvig.}

Eckernførde kreds, se nr. 24, 110, 129, 188, 216, 335, 340. Borreby s.: 237) H. J. Kuhlmann: Die Baugeschichte des Borbyer Kirchturms, Jb. E. 1953, s. 56-70. - 238) H. J. Kuhlmann: Ein unbekannter Entwurf Axel Bundsens für den Borbyer Kirchturm 1807, H. 1954, s. 10-12. - 239) H. J. Kuhlmann: Die Borbyer Windmühle 1474-1911 (her stamtavle over slægten Bruhn, der ejede mollen 1859-1911) Jb. E. 1954, s. 17-32. - Se endv. nr. 26 og 42. - Dänischwohld, se nr. 215. - Eckernförde: 240) Fr. Hoffmann: Das Bevölkerungsbild der Stadt Eckernförde um die Wende zum 19. Jahrh., Jb. E. 1953, s. 9-18. - Se endv. nr. 17. Hytten amt: 241) H. Bülck: Der Name Hütten, Jb. E. 1953, s. 45-48. 242) H. J. Kuhlmann: Die Grenzsteine des Amtes Hütten, H. 1953, s. 1418, 217. - Ang. Hytten amt og provsti, se endv. nr. 3, 178 og 342. Hytten s.: 243) W. Johnsen: Der Meister des Hüttener Altars, S-H. 1953, s. 7-8. - 244) O. Clausen: Wie die Bauern im 18. und 19. Jahrh. zu eigenem Land kamen. Die Verkoppelung veranschaulicht an der Gemeinde 
Brekendorf, Kirchspiel Hütten, Jb. E. 1954, s. 51-68. - Krusendorf s.: 245) R. Bülck: Zur Baugeschichte der Kirche Krusendorf, Jb. E. 1953, s. 71-75. - Riseby s.: 246) E. Schärff: 150 Jahre Charlottenhof und Erichshof, Jb. E. 1953, s. 49-55. - Se endv. nr. 348. — Sehested s.: 247) E. Schröder: Die Kirchen-Renovierung in Sehestedt im Jahre 1904, Jb. E. 1954, s. 133-140. Svans s., se nr. 46.

Ejders ted kreds : 248) R. Kuschert: Landesherrschaft und Selbstverwaltung in der Landschaft Eiderstedt unter den Gottorfern (1544-1713), Z. 1954, s. 50-138. - 249) H. Neumann: Die Staller verwalteten Eiderstedt. Aus der Geschichte der Eiderstedter Vögte, H. 1954, s. 272-273. - Se endv. nr. 120. - Koldenbüttel s.: 250) L. Oesau: Koldenbüttel im 30jährigen Kriege, H. 1953, s. 169-171. -

F e m e r n : 251) Fr. Rauers: Die Vetterschaften von Fehmarn, S-H. 1953, s. $20-22$. - Se endv. nr. 338 og 390.

Flensborg kreds: Se nr. 106 og 119. - Angel; 252) H. Guthmann: Angeln und die grosse Welt, Jb. A. 1954, s. 22-28. - Se endv. nr. $28,35,38,39,47,49,118,124,132,174,175$ og 214. - Eggebæk s.: 253) N. Tramm: Wie sah es in Eggebek vor 60-70 Jahren aus?, Jb. G. 1955, s. 167-176. - Eskris s.: 254) H. J. Kuhlmann: "Eine nie Döpe thor Kerken gemacht von Kopper . . «. Markus Dibler und die Taufe in Esgrus, H. 1953, s. 104-106. - Flensborg: Se nr. 13-15, 152, 226. - 255) R. Borchers: Flensburg-Weiche, S-H. 1953, s. 57-58. - Gelting s.: 256) H. J. Kuhlmann: Professor Gadso Koopmans, ein politischer Flüchtling als Gutsbesitzer von Oehe, Jb. A. 1953, s. 97-102. - Handved s.: 257) P. Selk: Die Sage von der Handewitter Kirche, Jb. G. 1953, s. 71-72. - Jørl s.: 258) O. Clausen: Wirtschaftliche und rechtliche Verhältnisse auf der mittelschleswigschen Geest von $1600-1650$, Jb. G. 1955, s. 84-101. - 259) W. Gondesen: Die königliche priviligierte Zollstelle in Lütken Kragstede, Jb. G. 1955, s. 185 -192. - 260) O. Clausen: Die Verkoppelung in Jörl, Jb. G. 1953, s. 62-66. - Kappel: 261) J. Nagel: Beitrag zur Baugeschichte der Kirche zu Kappeln, Jb. A. 1953, s. 163-167. - 262) H. Schmidt: Wie die vier Lehrer in Kappeln 1848 zum Kriege standen, Jb. A. 1953, s. 125-129. - Se endv. nr. 196. - Kværn S., se nr. 2. - Oversø s., se nr. 78. - Siversted s.: 263) E. Freytag: Kleine Chronik des Dorfes Jalm, Jb. G. 1955, s. 192-198. 264) E. Freytag: Ein Erbstreit um den priviligierten Hof Poppholz im Jahre 1719, Jb. A. 1953, s. 74-79. - 265) E. Freytag: Das Schicksal einer alten Kirchenglocke, H. 1953, s. 278-79. - 266) E. Freytag: Die Stammhufen und alten Katen in Süderschmedeby, Jb. A. 1954, s. 119-125. - Se endv. nr. 77 og 332. - Sterup s.: 267) E. Erichsen: Ein Altbauer Mittelangelns erzählt, Jb. A. 1953, s. 20-23. - Store Solt s., se nr. 350. - Store Vi s.: 268) P. Ingwersen: Die Geschichte des Gutes Lindewitt bis 1650, Jb. G. 1955, s. 117-133. - 269) P. Ingwersen: Ein lindewittsches Speis-Register von 1670, H. 1953, s. 312-14; jvnfr. H. 1954, s. 8. - Sørup s.: 270) P. 
Schwennsen: Aus alten Aufzeichnungen. Klagen eines Landlehrers (Svensby skole), H. 1953, s. 10-11. - Vanderup s.: 271) H. Gondesen: Die Geest im Wandel der Zeit. Beispiel Wanderup, Jb. G. 1954, s. 83-87. - Se endv. nr. 415.

Hus um kreds, Bredsted s.: 272) N. Möllgaard: Die Unvergessenen von Högel, Jb. G. 1955, s. 143-151. - Breklum s., se nr. 43. - Fjolde s., se nr. 376 og 386. - Habel hallig: 273) A. Bantelmann: Uber Veränderungen in der Flureinteilung der Hallig Habel, B. z. L. 1953, s. 175-179. Hoge hallig, se nr. 391. - Husum: 274) H. Klatt: Husum 350 Jahre Stadt. Aus ihrer geschichtlichen Entwicklung bis 1609, H. 1953, s. 197-200. 275) H. Appuhn, Husum. Die friesisch-niederdeutsche Stadt, S-H. 1953, s. 184-187. - 276) H. Hinz: Aus Husum frühester Geschichte, S-H. 1953, s. 182-183. - 277) Fr. Diestelhorst: Husumer Stadtrechnungen aus dem 16. Jahrh., H. 1953, s. 211-214. - 278) H. Siebel: Die Festsaaldecke aus dem 17. Jahrh. im Nebenhaus der einstigen Husumer Münze am Markt, $H$. 1954, s. 196-198, - Se endv, nr. 16, 150 og 366. - Ostenfeld s.: 279) K. Feddèrsen: Eulenspiegeleien um Gussohm aus Ostenfeld; Jb. G. 1955, s. 176-179. - Se endv. nr. 150, $202-0 g$ 203. - Langenæs hallig: 280) $\mathrm{H}$. Brandt: Als der Urgrossvater die Urgrossmutter nahm, H. 1953, s. 326-328. - Mildsted s., se nr. 33. - Nordstrand: 281) H. Kruse: Gerechtigkeit für Rungholt, S-H. 1953, s. 284-286. - Svabsted s.: 282) H. Hinz: Landschaft und Besiedlung im Kirchspiel Schwabstedt, H. 1953, s. 161-165. - 283) H. Meyer: Das Schwabstedter Bischofsschloss nicht 1730, sondern 1705 abgebrochen, H. 1953, s. 165-167. - Svesing s.: 284) P. Ingwersen: Der Bischof von Schleswig kauft 1513 das Gut Süderholz und Festestellen in Oster- und Westerohrstedt und Oldersbek, Jb. G. 1955, s. 204-205. Se endv. nr. 396. - Südfall hallig: 285) A. Busch: Flurnamen und Fluruntersuchungen in der Gemarkung Hallig Südfall, N. 1954, s. 108-116. Trelstorp s.: 286) H. Gerhard: Die Forstgenossenschaft Bohmstedt, ein Vorbild für die Neubegründung von Bauernwald, Jb. G. 1955, s. 12-22.

Rendsborg kreds : 287) G. Reimer: Vom Amte Rendsburg 15401800 , Z. 1954 , s. $139-205$. - 288) G. Reimer: Die Abfinıdung der Walddörfer aus dem Rendsburger Walde, Jb. R. 1954, s. 112-126. - 289) E. Stürtz: Dahinten auf der Lohheide, Jb. R. 1954, s. 90-105. - 290) G. Reimer: Das Nübbler Lehen, Jb. R. 1953, s. 96-98. - 291) H. Sievers: Ein Dorf im Eiderderknie (Hohner Harde) vor der Verkoppelung (omfatter byerne Hohn, Hamdorf, Elsdorf og Bargfeldt), Jb. R. 1953, s. 70-95. - Se endv. nr. 41, 101, 102, 130, 333. - Hohns s.: 292) H. Sievers: Das Schicksal der Osterhamn (Elsdorfer Gehege) bei der Feldauftheilung 1782, Jb. R. 1954, s. 105-112. - Rendsborg: 293) E. Hoffmann: Rendsburg, die Festungs- und Handelsstadt, Si-H. 1953, s. 132-133. - 204) Fr. Ross: Rendsburg, die Industrie- und Bauernstadt, S-H. 1953, s. 129-131. - 295) Th. O. Achelis u. E. Assmann: Der »Eiderstein" von Rendsburg, S-H. 1953, s. 69-70. - 296) G. Reinhardt: Hoch- 
burg schlesw.-holst. Gedankens. Rendsburgs Bedeutung im Ringen um die deutsche Zukunft Schlesw.-Holst.'s 1848-1868, S-H. 1953, s. 133-136. 297) Th. O. Achelis: Ein Streit um die Rendsburger Stadtfahne vor 100 Jahren, H. 1953, s. 262. - 298) H. Ramm: Einwohnerzahlen der Stadt Rendsburg von 1495 bis 1816, Jb. R. 1953, s. 37-38. - 299) G. Reimer: Die erste Befestigung Rendsburgs 1536-1541, Jb. R. 1953, s. 18-21. - 300) K. Müller: Rendsburger Miniaturen I-II, Jb. R. 1953, s. $39-45,1954$, s. $17-21$. 301) H. J. Kuhlmann: Die Rendsburger Glockengieserei 1757-1871, Jb. R. 1953, s. 24-36. - 302) A. Kuehn: Rendsburg und der Nordsee-Kanal, Jb. R. 1954, s. 7-16. - Se endv. nr. 6, 148-149. - Rendsborg Kristkirkes landsogn: 303) H. Schlothfeldt: Der Fockbeker Armensee mit seiner Umgebung und dem alten Streit um das Besitzerrecht, Jb. R. 1954, s. 87-90. 304) H. Schlothfeldt: Die Fockbeker Medardusgilde, erneuert im Jahre 1649 , Jb. R. 1953, s. 99-108.

Slesvig kreds: Se nr. 289. - Arns hrd., se nr. 5. - 305) H. Jürgensen: Die Marienkirche zu Boren, eine spätromanische Backsteinkirche, wieder eine romanische Kirche?, Jb. A. 1953, s. 147-162. - Eggebæk s.: 306) N. Tramm: Schulstreik in Langstedt 1799, Jb. G. 1953, s. 73-78. (Langsted hører til Slesvig kreds, medens Eggebæk s. iøvrigt hører til Flensborg kreds.) - Fredériksstad: 307) H. Schmidt: Friedrichstadt, eine holländische Gründung in Schlesw.-Holst., H. 1953, s. 137-144. - 308) E. HoffmannFriedrichstadt, das "Klein Amsterdam" an der unteren Eider, S-H. 1953, s. 111-112. - 309) Fr. Diestelhorst: Das Postwesen in Friedrichstadt bis zum Ende des 17. Jahrh., H. 1953, s. 132-136. - 310) K. Seidel: Binsen in Friedrichstadt und an der Eider, H. 1953, s. 145-147. (Ang. fletning af sivmåtter) - 311) S. Windmüller: Aus der Geschichte der Adler-Apotheke zu Friedrichstadt, H. 1953, s. 146-147. - 312) H. Chr. Saggau: Der Marktbrunnen in Friednichstadt, H. 1953, s. 125-126. - Se endv. nr. 14. Hedeby, se nr. 50, 51, 60, 315. - Krop s.: 313) K. Albers: Die Schulverhältnisse im Kirchspiel Kropp im 17. und 18. Jahrh., Jb. G. 1954, s. 88-99. 314) K. Albers: Bilder aus dem Schulleben des 19. Jahrh.s im Kirchspiel Kropp, Jb. G. 1955, s. 152-167. - Se endv. nr. 21. - Satrup s., se nr. 37. Slesvig: 315) J. Thomsen: 1150 Jahre Sliesthorp - Haithabu - Schleswig, H. 1954, s. 81-84. -- 316) J. Thomsen: 1150 Jahre vom alten Sliestorp zum heutigen Schleswig, Jb. A. 1954, s. 29-36. - 317) J. Thomsen: Was war die mittelalterliche St. Knuds-Gilde?, S-H. 1953, s. 240-41. - 318) H. Appuhn: Erhaltungsarbeiten am Schleswiger Dom, H. 1953, s. 221-23. 319) H. Appuhn: Die Wiederentdeckung des Bordesholmer Altars, K. S-H. 1954, s. 98-107. - 320) I. Schlepps: Der Hirschsaal und die Stuckaturen im Schloss Gottorp, N. 1954, s. 60-75. - 321) E. Petersen: Der Gottorfer Riesenglobus und sein Schicksal, S-H. 1953, s. 53-54. - 322) G. Wietek: Das Palais zu Schleswig, K. S-H. 1953, s. 174-185. - Se endv. nr. 60, 135, 144, 145, 206. - Slesvig, St. Michaelis lands., se nr. 29, 147, 229. - 
Struckstrup s.: 323) W. Philipsen: Die Fluraufteilung in der Gemeinde Struxdorf, Jb. A. 1953, s. 88-96. - 324) W. Philipsen: Geschichte der Schule von Struxdorf, Jb. A. 1954, s. 150-164. - Sønder Stapel s.: 325) Fr. Saeftel: Die Scheune von Peter Dau-Schmidt in Norderstapel, H. 1954, s. 36-38. - Tolk s.: 326) J. Thomsen: Geschichte des Hofes Neu-Tolkschuby, Jb. A. 1953, s. 79-88. - Treja s.: 327) Chr. Thiesen: Treia unter bischöflicher Landeshoheit, Jb. G. 1954, s. 73-80. - 328) Chr. Thiesen: Schulfragen während des Agendensstreits in Treia, Jb. G. 1955, s. 32-34. Tøstrup s., se nr. 122, 123.

Sydtønder kreds: Se nr. 70, 190, 217-221. - Amrum, se nr. 31. - Braderup s.: se nr. 221. - Galmsbol s., se nr. 208. - Karlum s.: se nr. 221. - Keitum s. 329) H. Reimnitz: Die Keitumer Kirche, S-H. 1954, s. 66 -67. - Medelby s., se nr. 125.

\section{Personalhistorie}

Almindelig.

330) C. Piepgras: Einführung in die praktische Familienforschung, M., h. 1. s. $2-4$, h. 2 , s. $1-3$, h. 3, s. 9-13. - 331) D. Wichmann: Schleswiger Geburts- und Verwandtschaftsbriefe des 18. Jahrh., M. h. 5, s. 48-61, h. 6, s. 69-80. - 332) E. Freytag: Auswärtige im Trauregister der Kirchengemeinde Sieverstedt (Propstei Flensburg) 1678-1742, Z. N.F. 1954, s. 22-24. - 333) G. Reimer: Verbreitung der Familiennamen im Amte Rendsburg nach der Rendsburger Amtsrechnung von 1540, M., h. 6, s. 65-69. 334) Th. O. Achelis: Erinnerungen aus dem Jahre 1864, Jb. A. 1954, s. 142-146. - 335) Sippen- und Familientage im Kreise Eckernförde (slægterne Bielfeldt, Missfeldt og Tams), Jb. E. 1954, s. 149-165. - 336) Th. O. Achelis: Die Bedeutung der Universitätsmatrikeln für den Familenforscher, N. F. $1952-53$, s. $62-65$. - 337) Th. O. Achelis: Matrikel der Studenten aus dem Herzogtum Schleswig, M. h. 3, s. 13-16. - 338) Th. O. Achelis: Studenten von der Insel Fehmarn 1517-1800, N. F. 1952-53, s. 147-150, 173-176. - 339) Th. O. Achelis: Von Schleswigschen Studenten 15171864, Z. N. F. 1954, s. 4-7. - 340) Th. O. Achelis: Studenten aus Schwansen $1517-1864$, Jb. E. 1953 , s. $19-28,1954$, s. 141 . - 341) C. J. Pape: Beamtengeschichte Nordelbingens, familiekundlich gesehen, Z. N.F. 1954, s. 109-113. - 342) Jon. Smith: Amtsschreiber und Amtsverwalter des Amtes Hütten, Jb. E. 1953, s. 29-39. - 343) R. Bülck: Schlesw.-holst. Geistliche im Spiegel ihrer Autobiographien II, Schr. 2. rk. 12. bd. s. 83-108. 344) Th. O. Achelis: Mecklenburg-schwerinsche Pastoren schlesw.-holst. Herkunft und schlesw.-holst. Pastoren mecklenburg-schwerinscher Herkunft, Z. N. F. 1952, s. 33-36, 61-66. - 345) Th. O. Achelis: Söhne der Stadt Lüneburg als Pastoren in Schlesw.-Holst., Z. N. F. 1954, s. 102-108. 346) N. Still: Genealogische Beiträge zur Pastorengeschichte im niederelbischen Holstein, Z. N. F. 1954, s. 121-136. - 347) G. Dehning: Verzeichnis der von 1791-1855 im Tonderschen Seminar ausgebildeten Zöglinge, 
Z. N. F. 1951, s. 56 ff, jvnfr. nr. 382. - 348) W. Schmidt: Verzeichnis der Leibeigenen des adligen Gutes Stubbe in Schwansen vom Jahre 1736, M. h. 3, s. 19-20. - 349) H. A. Plöhn: Register der "Hexen« in Schlesw.-Holst., Z. N. F. 1952, s. 66-67. Supplement ved E. Freytag Z. N. F. 1953, s. 15. 350) H. Hansen: Aus Gross Solt: Drei Gräber (Eiler Hagerup 1817-63, præst, J. C. v. Bernstorff, 1799-1867, skovrider, Karl Bock, 1861-1945. botaniker), Jb. A. 1954. s. 126-131. - Alm. personalhist., se endv. nr. 138 og 266, samt M., hvor der i hvert hæefte findes meddelelser ang. nyt inden for den personalhistoriske forskning.

\section{Speciel.}

353) Andersen, Hermann, 1830-1889, lærer, Olderup, Haderslev og Skrydstrup, H. 1954, s. 98-100. - 354) Andrup, Otto, museumsdirektør, Frederiksborg, S-H. 1953, s. 262. - 355) Asmussen, Georg, 1854-1933, skibsbygger, afholdsagitator, S-H. 1954, s. 111, H. 1954, s. 123-24. Bernstorff, J. C. V., 1799-1867, skovrider, se nr. 350. - 356] Bertheau: Th. Voss: Martin Bertheau, der Hymnologe, Schr. 2. rk. 12. bd., s. 147-162. - Bielfeldt, se nr. 335. - 357) Bluhme: C. Friederici: Zwei Borener Pastorengeschlechter, Jb. A. 1953, s. 130-146. - Bock, Karl, 1861-1945, botaniker, se nr. 350. - 358) Boyens, Georg, 1627-85, bysekretær, Tønder, H. 1953, s. 39-43. - 359, Braren, Lorenz, d. 1953, fabrikant, lokal- og personalhistoriker, S-H. 1953, s. 88. - 360) Braren, Oluf, 1787-1839, kunstmaler, Før, S-H. 1953, s. 39-41. - Bruhn, slægten, Borreby mølle, se nr. 239. - 361) Bubbe, H. F., f. 1873, lærer i Åbenrå, sen. lærer sydpå, H. 1953, s. 107. - Bundsen, Axel, arkitekt, se nr. 238. - 362) Busch-Alsen. Hans, nulevende maler, H. 1953, s. 56-57. - 363) Bülck, Rudolf, 1880-1954, biblioteksmand, historiker, Schr, 2, rk. 12 bd. s. $180-181$, N. 1954, s. 7-22. - 364) Böhndel, Conrad Chr. Aug., f. 1779, maler i Slesvig, Jb. E. 1954, s. 166. - Carl, landgreve af Hessen-Cassel, 1744-1836, se nr. 114. Carstens, Asmus Jacob, se nr. 158. - 365) Caspersen, Jürgen, 1705-76, Oksager, Angel, Jb. A. 1953, s. 115-117. - 366) Cornelissen, Berend, ca. 1592-1684, billedskærer, Husum, S-H. 1953, s. 188. -- 367) Dibler, Michel, d. 1642, klokkestøber, Flensborg, N. 1953, s. 58-84; jvnfr. endv, nr. $15 \mathrm{y}$ og 254. - 368) Dorothea Christine, hertuginde af Reinfeld, H. 1954, s. 42-44. - 369) Dreesen, Adalbert, 1828-1919, lærer, forfatter, Åbenrå, H. 1953 , s. 45-46, 120. - 370) Dreyer. Marchtaler, H.: Die Familien der Hamburger Convoykapitäne (Konvojkapt. Mathias Dreyers efterslægt, hvoraf en del i Senderjylland) Z. N.F. 1952, s. 18-21. - 371) Ewoldt, f. 1874, amtsdommer i Sønderborg, S-H. 1954, s. 184. - 372) Fabricius, Christoph Heinrich Detlev, 1802-80. officer, H. 1953, s. 153-159. Friederici, slægten se nr. 357. - 373) Gerritz, Theodor, ca. 1603-1653, diakon i Oldenswort, H. 1953, s. 117, - 374) Godt. Th. O. Achelis: Die Wahlpredigt des späteren Generalsuperintendenten Bertel Petersen Godt 
(1842), H. 1954, s. 39. - Hagerup, Eiler, 1817-63, præst, se nr. 350. 375) Hansen, Christian Peter, 1803-70, samler og lokalhistoriker, S-H. 1953, s. 241-42. - 376) Hansen, J. Jensen: Pastor Hans Hansen in Viöl und die politischen Ereignisse der Jahre 1845-51, Jb. G. 1955, s. 134-144. - 377) Hansen Harald, f. 1884, amtmand og diggreve, Kejtum, S-H. 1954, s. 153. - 378) Hansen. J. Nagel: Aus dem Leben und Wirken eines Angler Bauern um die Mitte des vorigen Jahrh.s (Lorenz Hansen 1809-81. Lyshøj, Husby s.), Jb. A. 1954, s. 132-134. - 379) Hansen, Simon Volkert, 181589, maler, S-H. 1954, s. 108-110. - 380) Heit, Friedrich, f. 1870, billedskærer, Flensborg, sen. Neumünster, H. 1954, s. 288-89. - Helmbert de Visbeke, bískop, se nr. 104. - 381) Hinrichsen, Ludwig, Kappel, f. 1872, forfatter, selvbiografiske optegnelser, Jb. A. 1954, s. 10-13. - 382) Horns. G. Dehning: Hans Jakob Horns, Lehrer, Organist und Küster in Jevenstedt. (1811-1907). (Her omtales s. 11 f et manuskript vedr. seminarister fra Tønder seminarium), Jb. R. 1953, s. 9-13. - 383) Iwersen, Jens, d. 1954, professor, S-H. 1954, s. 217. - 384) Jensen, Emil, billedhugger, nulevende født i Nordslesvig, S-H. 1953, s. 159-160. - 385) Jensen. Th. O. Achelis: Hans Jensen, Bürger und Gastwirt in Flensburg und seine Herkunft (1768-1847), Jb. A. 1953, s. 118-124. - 386) Jensen. J. Jensen: Lorenz Jensen aus Kollund, Kirchspiel Viöl. Leben und Werk eines bedeutenden schleswigschen Bauern (1740-1807), Jb. G. 1954, s. 105 -114. - 387) Jessen. Th. O. Achelis: Die Brüder Peter Hinrich und Christian Peter Jessen. Ein Beitrag zur Geschichte des Haderslebener Johanneums (som bilag anetavle), Schr. 2. rk., 12. bd., s. 109-129. - 388) Kahlke, Max, 1892-1928, maler, K. S-H. 1954, s. 154-160. - 389) Kelelsen, Bruno, d. 1945, lærer, folklorist, lokalhistoriker, S-H. 1953, s. 173, H. 1954, s. 41-42, se endv. nr. 4. - 390) Knudsen, Broder, 1811-86, amtmand på Femern 1851-64, H. 1954, s. 116-117. - 391) Koch, Samuel Friedrich, 1806-62, præst på Hoge, H. 1954, s. 259-62. - Koopmans, Gadso, professor, godsejer på $\varnothing$, se nr. 256. - 392) Krieger, Ph. H., 1852-1932, seminarielærer i Tønder, sen. forstander i Åbenrả, H. 1953, s. 49. - Liliencron. 393) G. Reinking: Dem Gedenken Detlef von Liliencrons, $H$. 1954 , s. $223-24$; jvnfr. s. 326. - 394) H. B. Jessen: Liliencronbriefe, N. 1953, s. 171-174. - 395) Lippe. H. J. Kuhlmann: Ein "Gottorper Künstler « in Eckernförde. Der Goldschmied Adam v. der Lippe (ca. 1600), K. S-H 1955, s. 179-80. - 356) Lorentzen, Hans, 1729-1805, „Rechenmann", Svesing, Jb. G. 1953, s. 67-70. -- 397) Lund, Jens Martin, 1739-84, kunstmaler, H. 1954, s. $49-52,246$. - 398) Lübke, Friedrich Wilhelm, d. 1954, ministerpræsident, S-H. 1954, s. 291-92. - 399) Löhmann, Frieda, f. Lassen, 1873 -1954, Flensborg, S-H 1954 ,s. 151-152. - 400) Massmann, Karl, f. 1889, Landesbankdirektor, S-H. 1954, s. 217. - 401) Matthiesen, Thomas, f. 1874, præst, Schr. 2. rk., 12 bd., s. V-VIII. - 402) Meyer Johs., 1606-74, kartograf, H. 1953, s. 108. - Missfeldt, slagten, se nr. 335. - 403) Moltke, Carl, 
1798-1866, gehejmestatsminister, S-H. 1953, s. 213-216. - 404) Mommsen, Theodor, d, 1903, historiker, S-H. 1953, s. 255-56. - 405) Mosheim. Th. O. Achelis: Zur Lebensgeschichte Johann Lorenz Mosheims (afslog 1749 at blive generalsuperintendent), Schr. 2. rk., 12. bd., s. $16 \varepsilon-174$. 406) Møller, Theodor, 1873-1953, lærer, fotograf, lokalhistoriker, N. 1954, s. $22-29$, H. 1953 , s. $73-77,78-86,112,317$, S-H. 1953, s. $71-72$. 407) Nebel, Kay, 1888-1953, kunstmaler, S-H. 1953, s. 81-82. - 408) Ortmann, Richard, 1879-1953, seminarielærer, Tonder, sen. Studienrat, Nibøl, H. 1953, s. 190, S-H. 1953, s. 88-89. - Ovens, Friedrich Adolf, maler, se nr. 154. - Ovens, Jürgen, maler, se nr. 155-156. - Pahl, Hans, billedskærer, d. 1714, se nr. 148. - 409) Pauls, Volquart, 1884-1954, bibliotekar, historiker, S-H. 1954, s. 30-32, 151, H. 1954, s. 35-36. - Peper, Hans, billedskærer i Rendsborg, se nr. 149. - 410) Petersen, Andreas, f. 1914, kunstmaler, H. 1954, s. 45-47. - 411) Petersen, August, 1792-1830, herredsfoged i Augustenborg, H. 1954, s. 62-63. - 412) Petersen, Carl Dietrich, f. 1867, lærer, filolog, H. 1953, s. 48. - Petersen, se endv, nr. 108. - 413) Plöhn. H. A. Plöhn: Ein Familienname wird in die Vergangenheit verfolgt, H. 1954, s. 92-95. - 414) H. A. Plöhn: Der Name Plön/Plöhn im Dreieck Eckernförde-Schleswig-Rendsburg, Jb. E. 1954, s. 142-148, 415) Portner, Johann, ca. 1600, præst, Vanderup, Jb. G. 1955, s. 198-203. Rantzau, adelsslægt på Lindeved, se nr. 268. - 416) Richter. E. Freytag: Die Gebrüder Johann Adam und Peter Richter, zwei schlesw.-holst. Baumeister des 18. Jahrh.s und ihre Familie, Z.N.F. 1954, s. 65-75. Richter, J. A., se endv. nr. 261. - Rode, adelsslægt på Lindeved, se nr. 268. - 417) Rumohr. C. v. Lorck: Die Bildnisse Carl Friedrich von Rumohrs (1785-1843), K. S-H. 1954, s. 108-124. - Sander, Hans, billedskærer, Rendsborg, se nr. 149. - Scheel, Otto, historiker, 1876-1954, se nr. 108. 418) Scheffner, Johan Heinrich, 1825-1892, rektor i Tønder, H. 1953, s. 53-55. - 419) Schmeisser, Felix, redaktør, lokalhistoriker, Husum, S-H. 1553, s. 261. - 420) Schmidt, Harry, f. 1883, historiker, H. 1953, s. 88-89, S-H. 1953, s. 87, Jb. R. 1953, s. 13-17. - 421) Schmidt, Johs., f. 1869, præst, grænsepolitiker, S-H. 1953, s. 204-05, 1954, s. 154. - 422) Schriewer, Franz, f. 1953, bibliotekar, grænsepolitiker, Flensborg, S-H. 1953, s. 142-43. - 423) Schwindrazheim, O., d. 1952, maler, professor, H. 1953, s. 94. 424) Spethmann, Johannes, d. 1951, møller, botaniker, Seemühlen v. Rendsborg, Jb. R. 1953, s. 7-9. - 425) Stierling, Hubert, d. 1950, museumsdirektør, Altona, N. 1953, s. 7-12. - 426) Stork, Karl, 1905-53, kunsthistoriker, N. 1954 , s. 29-34. - Storm. 427) M. C. Mangels: Uber Wold Nommensen und Ingwer Woldsen, zwei Vorfahren Theodor Storms, H. 1953, s. 245-47. - 428) E. Kammerhoff: Theodor Storm. Ein Erinnerungsbild, H. 1953, s. 200-205. - 429) W. Jürgensen: Die Begegnung zwischen. Theodor Storm und Theodor Fontane. Ein Beitrag zum Charakterbild beider Dichter und ihrer Zeit, N. 1953, s. 161-170. - 430) H. Schmidt: Zwei Geburtstagsge- 
dichte Theodor Fontanes für Theodor Storm, S-H. 1953, s. 189-190. 431) E. O. Wooley: Theodor Storm in Amerika, S-H. 1954, s. 79-80. 432) Struense, Maria Sophia Friederike, d. 1787, Schr. 2 rk., 12. bd., s. 174-175. - Tams, slægten, se nr. 335. - thor Straten, slægten, se nr. 326. - Todsen, Peter, 1789-1855, stænderdeputeret, se nr. 70. - 433) Voss. Johann Heinrich, N. 1953, s. 149-60, - 434) Wohlhaupter, Eugen d. 1946, retshistoriker, S-H. 1953, s. 19-20. - 435) Wolff, Chr., f. 1879, forlægger, Flensborg, S-H. 1954, s. 152. - Wöhlk, Nico, 1887-1950, maler, se nr. 157. - 436) Zillinger, Erwin, f. 1893, organist, komponist, S-H. 1953, s. 173. - 437) Oehlert. R. Faasch: David Georg Friedrich Oehlert. Soldat, Kolonist und Ahnherr des Geschlechtes im schleswiger Raum, Jb. G. 1954, s. 124-131. - Oest, Nikolaus, 1719-98, præst, se nr. 165. 